\title{
A Study on the Correlation among FD-FI Cognitive Style, Working Memory Capacity and English Reading Performance among College EFL Learners
}

\author{
Yuhan Ge* \\ Southeast University, Nanjing, China
}

\begin{abstract}
In the past few decades, there have been eminent interests in reading performance as essential means for language input. In view of that, extensive studies have been conducted to explore the factors that affect reading performance from various aspects. In the cognitive psychology field, some studies have examined the relationship between field dependent-field independent (FD-FI) cognitive styles and working memory capacity (WMC) on English reading, respectively. However, only limited studies focused on the correlation among FD-FI cognitive styles, WMC and English reading performance. Therefore, this study was conducted to explain these correlations. A total of 42 intermediate "English as Foreign Language" (EFL) learners participated in this study. In order to measure the learners' FD-FI cognitive style, WMC and English reading performance, the Cognitive Style Figures Test, reading span task and the International English Language Test System (IELTS) reading test were adopted, respectively. Data analyses such as Pearson's correlation, independent sample t-test and two-way ANOVA were done using Statistical Package for the Social Science (SPSS) version 25. The results suggested a statistically significant correlation between FD-FI cognitive style and WM with English reading performance, respectively. The main effect of WM and FD-FI cognitive style is significant while the interaction between them is not significant in reading performance.
\end{abstract}

Keywords: FD-FI cognitive style; Working memory; English reading performance

Publication date: May, 2021; Publication online: 31 May, 2021

*Corresponding author: Yuhan Ge, geyuhan2021@163.com

\section{Introduction}

Reading is one of the essential means for language input. The English reading skill reflects a learners' proficiency in processing text information. For college EFL learners, their English reading skills may influence their professional learning as they are required to read challenging academic papers. Therefore, cultivating students' English reading ability is regarded as one of the most important objectives of colleges' English education.

The factors affecting language reading performance has been extensively explored and discussed by researchers. This is to further understand the English reading process and provide effective guidelines for both teachers and learners, especially in setting for second language learners.
Among enormous factors, cognitive styles should be taken into consideration by language teachers and learners as they may influence or interfere with the learners' reading performance and comprehension. The term "cognitive styles," can be defined as information processing habits representing the learner's mode of perceiving, thinking, problem solving, and remembering. ${ }^{[1]}$ Cognitive styles manifest themselves in various activities and are interwoven with other behavioral or physiological factors. One cognitive style that has been reported to affect English reading is field dependence (FD) / field independence (FI) cognitive style. This style is defined as the extent to which a person can perceptually separate an object from the surrounding field rather than treating it as 
embedded within the field. ${ }^{[2]}$ FD involves personal orientation, holistic views, dependence, and social sensitivity while FI involves impersonal orientation, analytical views, independence, and social unawareness. ${ }^{[3]}$ Explicitly, people with FD cognitive style are more relational and tend to perceive the whole situation or context. Instead, those with FI cognitive style are able to separate details from the surrounding situation or context.

Another essential cognitive factor is working memory, which refers to a system for temporary storage of information, which is indispensable for performing complex tasks like comprehension, problem-solving, reasoning, learning and decisionmaking. ${ }^{[4]}$ Regarded as the cognitive center of human beings, working memory has become the interest in the research field of cognitive psychology and linguistics.

\section{Literature Review}

\subsection{FD-FI cognitive style}

FD-FI cognitive style refers to an individual's tendency to process information. It is widely accepted that learners with different cognitive styles tend to show different behaviors in the process of learning languages.

\subsubsection{Definition of FD-FI cognitive style}

In the past few years, many researchers have taken an interest in FD and FI cognitive styles and have defined FD-FI cognitive styles according to different perspectives. The concept of this term was first proposed by Witkin, whereby "field" refers to the surroundings that a person is in, that influences people's cognition. ${ }^{[5]}$ Field-dependent learners rely more on the external reference of their surroundings to obtain knowledge and information, while field-independent learners are not susceptible to external influences or interference, whereby they tend to depend on their internal reference. According to Ehrman, FI refers to a person's ability to separate individual factors from the whole, while field dependence means that individuals are always easily affected by the environment. ${ }^{[6]}$ Cassidy points out that learners with FI cognitive style operate with an internal reference system and instinctively use self-directed goals as motivation to construct their own learning and define their own learning strategies. ${ }^{[7]}$ In summary, as learners' cognitive style is inextricably connected with their personality and environment, it is relatively stable in most cases.

\subsubsection{Measurement of FD-FI cognitive style}

Sternberg states that cognitive styles can be divided into three types: cognition, personality and activity. Among them, "cognition-centered" cognitive style is linked to personal abilities and can be measured by standardized tests. Witkin designed several measurement tools, including Rod and Frame Test, Body Adjust Test, Embedded Figure Test, etc. Among these tools, Embedded Figure Test is most widely adopted in research. Therefore, this study also used this test to measure the FD-FI cognitive style.

\subsection{Working memory}

\subsubsection{Definition of working memory}

Baddeley and Hitch introduced the concept of working memory that derives from psychological study of 'short-term' memory. Short-term memory is a limited system whereby information can only be stored for a short period of time. ${ }^{[8]}$ However, WM not only refers to the storage of information, but also the process of information in complicated cognitive activities. According to Baddeley, working memory is a limited system for temporary storage of information, which is essential for completing complex tasks like comprehension, problem-solving, reasoning, decision-making, learning, etc. ${ }^{[9]}$

\subsubsection{Models of working memory}

The model of working memory is a multicomponent system that was proposed by Baddeley and Hitch. It is composed of a supervisory system, namely the central executive that regulates and drives two subsidiary systems, which are the phonological loop and the visuospatial sketchpad. ${ }^{[10]}$ This system also copes with complex 
cognitive tasks such problem-solving, reasoning and mental arithmetic. The phonological loop is the most extensively investigated system of working memory. It is assumed that this component encompasses two sub-components: a phonological store that represents materials in the form of phonological code which are subjected to decay over time, and an articulatory rehearsal system which refreshes these materials in the phonological store and retains memory. The visuospatial sketchpad is used to temporarily store and manipulate information in a visual or spatial form. However, this model is challenged by empirical studies claiming that it lacks a system that integrates phonological, visual and possibly other types of information which then links to the longterm memory.

Therefore, Baddeley added an episode buffer to the original central executive model, which is capable to integrate various pieces of information from various kinds of sources into limited episodes or chunks. This model has been extensively adopted to deal with a range of issues related to higher-level human cognitive functions (See Figure $1)$.

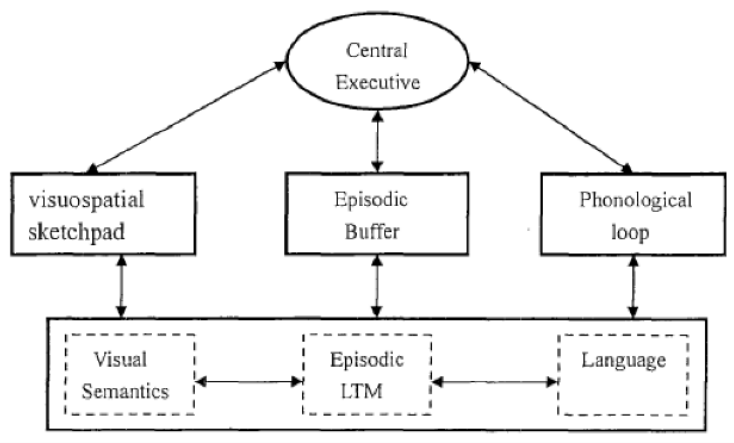

Figure 1. The WM Model proposed by Baddeley

\subsubsection{Measurement of working memory}

According to Daneman, if an individual does not rehearse, the information can only be retained for $15-30$ s or even less in the working memory. ${ }^{[11]}$ Miller proposed that the seminal quantification of this limited capacity is about seven plus or minus two $(7 \pm 2) .{ }^{[12]}$ The actual capacity of short-term memory should be $2-4$ chunks of information when interferences from other sources of information are excluded.
There are various measurements employed to test the capacity or efficiency of an individual's resource processing. Carpenter proposed the "reading span task" in which the process of presenting an item and recalling it is interrupted by another task, for example, making judgement. The reading span task has been proved to be the most reliable and standard instrument to measure the WMC. Moreover, it is a good predictor for reading comprehension because it involves both the language storage and processing. This study adopts the reading span task of Cai et al (2005) revised from that of Daneman and Carpenter which will be further discussed in the methodology section.

\subsection{Reading comprehension}

\subsubsection{Definition of reading comprehension}

According to Goodman, reading is a complex process of psycho-linguistic activity in which readers interact with the author and text. ${ }^{[13]}$ Reading comprehension is the process of constructing meaning from a written text. In this paper, reading comprehension is regarded as a complex cognitive process as readers, not only have to understand the superficial meaning of the passage, but also grasp the profound connotation that the author is conveying.

\subsubsection{Theories of reading comprehension}

From the perspective of cognitive psychology, two theories are introduced. The first is "schema theory," proposed by Widdowson in 1983, which defines reading as the interaction between the readers' basic knowledge and the information of the text. That is to say, the reading comprehension is based on previously acquired knowledge. In the process of reading, readers with more schemata tend to have better reading comprehension as they have more knowledge.

The second theory is "information theory" proposed by Carroll (2000). This theory describes the processing, organizing, and maintaining information obtained from the text. According to this theory, reading comprehension can be divided into three components: sensory storage, WM, and permanent memory. When sensors are triggered by 
environmental stimulus, information begins to process. The register sensor will hold the information for a short period of time and then the insight sensor begins to define the meaning of the information which will then be transferred to the $\mathrm{WM}$ and remain there for a limited time. Then, previously obtained information which is related to the new information will be withdrawn from the long-term memory and finally, the integration of previous information with the new information.

\subsection{Studies on the relationship between FD-FI cognitive style and English reading comprehension}

In recent decades, extensive research has been conducted to explore the factors that influence language learning. Cognitive style, which is one of the crucial factors, received enormous interests from scholars worldwide, especially the field dependence/field independence cognitive style.

Javier (1997) found that there exists a statistically significant relationship between FD-FI cognitive style and reading comprehension in both Spanish and English, which demonstrates that this cognitive style plays a part in reading comprehension.

Sabet \& Mohammadi studied the relationship between the same cognitive style and reading comprehension abilities of EFL learners, resulting in a significant difference between FD and FI learners. $^{[14]}$

Ali \& Hasan conducted a study among 305 students to determine the relationship among FDFI cognitive style, English reading and academic success. Results showed that the cognitive style correlates with reading comprehension score, English language learning and academic achievement with coefficient of determination of $8.8 \%, 9.2 \%$ and $11.6 \%$ respectively. ${ }^{[15]}$

Wu et al. (1993) focused on the relationship between cognitive style and English grades. 250 English major students were enrolled. Results showed that FI learners perform better in language test than FD learners.

In most cases, excellent foreign language learners are people with FI cognitive style. $\mathrm{Xu}$ studied FD-FI cognitive style of students from different majors, he discovered that art major students tend to have FD cognitive style, while science major students have FI cognitive style $(p<0.05)$. In addition, they generally perform better than those of arts major in English test $(p<0.05) .{ }^{[16]}$ However, in another study, Dai suggested that FI cognitive style does not have substantial effect upon English beginners' grades ( $\mathrm{r}=0.10)$, and there is no significant correlation between male learners' grades and FI cognitive style $(\mathrm{r}=.083) .{ }^{[17]}$

Hence, in literatures, there is no absolute agreement on the correlation between FD-FI cognitive style and language test scores.

\subsection{Studies on the relationship between WM and English reading comprehension}

Daneman \& Carpenter first explored individual differences in WM and the relationship between WM and English reading comprehension. The findings suggested that readers with high WM performed better in the reading comprehension test $(\mathrm{F}(3,16)=27.56, \mathrm{P}<0.01)$.

Later, Andy \& Ramzi conducted a study on 157 children aged from 9 to 12 to determine the relationship between $\mathrm{WM}$ and reading ability. The study showed that WM had correlation $(\mathrm{r}=0.37$ $0.47, \mathrm{P}<0.001)$ with reading fluency and reading comprehension $(\mathrm{r}=0.42-0.48, \mathrm{P}<0.001) .{ }^{[18]}$.

Gulcan et al. (2014) explored the relationship between WM and second language (L2) learning. Ninety-eight Turkish EFL learners were involved in the research. Results demonstrated that L2 reading comprehension was correlated with WM $(\mathrm{r}=0.235, \mathrm{P}<0.05)$.

Wei analyzed L2 WM and language proficiency on 65 sophomores majoring in English. The results demonstrated that the processing rate of WM grew significantly $(\mathrm{P}=0.045<0.05)$ with the improvement of the learners. ${ }^{[19]}$

The study of Kerry \& Emily found that there is a significant relationship between WM and reading $(\mathrm{r}=0.417, \mathrm{P}<0.001) .{ }^{[20]}$ 
2.6 Studies on the relationship between FD-FI cognitive style and English reading comprehension

Cognitive styles reflect how individuals process information, while working memory is related to information storage and processing. ${ }^{[21]}$ For this reason, it is necessary to explore the relationship among cognitive styles, WM and English reading comprehension grades.

Case (1974) argued that working memory is an information-processing system which enables FI individuals to outperform FD individuals in complex cognitive activities. Davis \& Frank (1979) stated that FI students have a greater capacity for efficient memory tasks.

Baillargeon et al. (1998) showed that students with FI cognitive style tend to have better WMC than those with FD cognitive style because FI learners have mastered several strategies to organize information.

The study of Bernard \& Delane focused on the "free-recall memory performance" and "spontaneous strategy use." Students were required to memorize a list of word with or without applying cognitive strategy. The results showed that FI learners recalled more words (adjusted $\mathrm{M}=21.35$ ) than FD learners (adjusted $M=19.49$ ).

Grimley \& Banner investigated the relationship among WM, cognitive styles, behavior and achievement. They conducted the study on a total of 205 13-year-old students. Data showed that students with analytic style $(\mathrm{M}=32.5, \mathrm{SD}=14.2)$ were more susceptible to the influence of WMC than those with wholistic style $(\mathrm{M}=37.5$, $\mathrm{SD}=13)$. $^{\text {[2] }}$

Alloway examined the relationship among WM, cognitive styles and adolescents' attainment. A total of 164 13-year-old students were engaged in the study. It was suggestive that WM can predict English learning outcomes. The univariate analysis showed that WM scores were not significantly different between students with different cognitive styles $(\mathrm{F}(1,155=1.23), \mathrm{P}=0.27)$. However, analytic learners with high WM $(\mathrm{M}=4.68, \mathrm{SD}=0.91)$ have better grades in the English test than those with low $\mathrm{WM}(\mathrm{M}=4.30, \mathrm{SD}=0.99){ }^{[23]}$
Although there are only a few studies on the correlation among FD-FI cognitive style, WM and English reading performance, the studies mentioned above have contributed to this study. However, in previous studies, there were some limitations such as inconsistent results, limited methods of data analysis, and narrow target populations. ${ }^{[24]}$ In regard to that, only minimal studies were done on postgraduates' subjects. English education has not been the focus among these group of people as the benchmark of their abilities were usually emphasized on the write-up of academic papers. However, English reading skills are essential for them to understand languagechallenging academic papers. Therefore, this study investigates the correlation among FD-FI cognitive style, WM, and English reading performance of college EFL learners and have chosen postgraduates as research subjects. This study applied the Pearson's correlation and independent sample t-test for data analysis.

\section{Methodology}

\subsection{Research question}

This study examined the correlation among FD-FI cognitive style, WM and English reading performance of college EFL learners. It aimed to answer the following research questions:

1. What is the relationship between FD-FI cognitive style and English reading performance?

2. What is the relationship between working memory and English reading performance?

3. What is the relationship among FD-FI cognitive style, working memory and English reading performance?

\subsection{Research subjects}

This study involved 42 postgraduate students from Southeast University. They have different majors, and their average English reading skill was at the intermediate level. Generally, they have learned English for more than 12 years. Their age ranged from 22 to 25 . They were informed about the purpose of the research prior the test and all of them were willing to participate in the research. 


\subsection{Research instruments}

\subsubsection{Cognitive Style Figure Test}

The Cognitive Style Figure Test which is revised from Witkin's Embedded Figure Test was adopted to measure the participants' FD-FI cognitive style. This test has been extensively applied in cognitive studies with a validity of 0.49 . In this test, geometric figures were presented to the participants, and they were required to find simple geometric figures that were embedded or hidden in relatively more complex diagrams. Scores were given accordingly for full and correct figures. The test had three sections, the first was an introduction, which provided instructions with some examples. The second section had three parts of complex figures followed by nine simple geometric figures. In total, there were 20 complex figures. Points were given accordingly, whereby 0.5 points each for the first two figures, 1 point each for the third and fourth figure, and 1.5 points each for the rest of the figures. Therefore, the total score was 24 points. For example, if a participant had accurately found one simple figure from the complex diagram, they would receive the corresponding score.

\subsubsection{Working memory test}

The reading span task designed by Cai was used in this study to measure WMC. It had been used by many scholars in WM tests in China and has high validity as well as reliability. The test was programmed with E-prime 2.0 and ran on MacBook Air. The test included a total of five types of sentence groups which were two-sentence group, three-sentence group, four-sentence group, fivesentence group and six-sentence group. Each sentence group has three sets of sentences. Among the 60 sentences, 30 were semantically correct and the other 30 were semantically wrong. These sentences were presented to the participants in Eprime from the two-sentence group to six-sentence group. The display of each sentence will last for 10 seconds on the screen, whereby the participants were required to determine if the sentence was semantically correct or wrong. If the sentence was semantically correct, the participants would tap on the alphabet "F" on the keyboard, if not, "J" would be selected. At the end of each set of sentences, participants were required to recall the last word of each sentence that was previously shown. Before the formal test, there was a trial session for the participants to familiarize with the procedure. Recalling the last words of the sentence represented the working memory storage, and correct judgement of semantically right sentences indicated the processing of working memory. If a participant chose correctly for 1 or 2 sentences in the two-sentence group, his or her working memory would have been regarded as 1 . If the participant does correctly with 3 sentences in the two-sentence group but failed in the 3 three-sentence group, his or her working memory will be given a score of 2 . The participants whose scores were below 3.5 were placed in the low WM group, and those with scores 4 and above were placed in the high WM group.

\subsubsection{Reading comprehension test}

An IELTS reading test was used to test the subjects' reading comprehension ability. There were 3 passages with a total of 40 questions, whereby a point was given for each question answered correctly. The IELTS reading test was carried out during two regular class periods. It took 60 minutes to finish the test. All the participants were carefully supervised by an examiner during the test, and they were not allowed to refer to any relevant information sources or discuss with others.

\subsection{Data collection and analysis}

All participants voluntarily took the three tests that were carried out in October 2020. The participants were informed about the purpose of the study, and that all the research information were confidential for the use in this research only. The whole experiment lasted for a week.

(Day 1) The Cognitive Style Figure Test was carried out on the first day during class. It took about 20 minutes to finish the test.

(Day 2-5) Then, the reading span task was 
programmed with E-prime 2.0 and ran on MacBook Air in the phonetics lab the following four days. It took approximately 20 minutes to finish the task. Each day, ten participants would have conducted the task and after the task each day, they were instructed not to disseminate the questions. All the participants were carefully supervised by the examiners during the task. The display order of the experimental items was completely randomized. At the beginning of the test, the relevant instructions were displayed in Mandarin. Participants were instructed to decide on whether the sentences were semantically right. Each sentence appeared on the screen for 10 seconds, and the participants were prompted to press ' $\mathrm{F}$ ' for semantically correct sentences or ' $\mathrm{J}$ ' for semantically incorrect sentences.

(Day 6) Finally, the IELTS reading test was carried out during two regular class periods. It took 60 minutes to complete the test. All the participants were carefully supervised by the examiner during the test, and they were not allowed to discuss or refer to any relevant information sources.

According to the research questions, the data analyzed were divided to three parts. To answer the first question, descriptive statistics of FD-FI cognitive style and English reading comprehension scores were presented. Pearson's correlation analysis was used to determine the relationship between FD-FI cognitive style and English reading performance. If the two variables were related, independent sample t-test was used to determine the significant difference between FD and FI subjects in English reading performance. To answer the second question, descriptive statistics of FD-FI cognitive style and English reading comprehension scores were presented. Then, Pearson's correlation analysis was used to determine the relationship between WM and English reading performance. If the variables were related, independent sample t-test was used to determine whether there was a significant difference between learners with high WMC and those with low WMC in English reading performance. To answer the third question, double factor variance analysis was used to determine the relationship among FD-FI cognitive style, WM and English reading scores. All data were analyzed by SPSS 25.

\section{Results and Discussions}

\subsection{Relationship between FD-FI cognitive style and English reading performance}

A total of 42 postgraduates participated in the experiment and the data collected were valid. In the Cognitive Style Test, scores were given according to the number of correct figures they have found. The higher the score they achieved, the higher the tendency of their cognitive style towards field independence (See Table 1).

Table 1. Descriptive statistics of FD-FI cognitive style and English reading performance

\begin{tabular}{lccccc}
\hline & N & Minimum & Maximum & Mean & Std Deviation \\
\hline FI-FD cognitive & 42 & 9.0 & 24.0 & 17.940 & 4.7719 \\
English reading performance & 42 & 14 & 38 & 26.33 & 5.393 \\
Valid N (listwise) & 42 & & & \\
\hline
\end{tabular}

Table 1 shows the descriptive statistics of FDFI cognitive style and English reading performance. The mean score for the FD-FI cognitive style was 17.940 and its' standard deviation was 4.7719. These showed that the participants' cognitive style was more towards field independence. In regard to the English reading comprehension test, the mean score was 26.33 and the standard deviation was 5.281, which meant that there were individual differences between the participants' reading comprehension ability.

To determine the relationship between FD-FI cognitive style and English reading performance, Pearson's correlation was used (see Table 2). 
Table 2. Correlation between FD-FI cognitive style and English reading performance

\begin{tabular}{llcc}
\hline & & FI-FD cognitive style & $\begin{array}{c}\text { English reading } \\
\text { comprehension }\end{array}$ \\
\hline FI-FD cognitive style & Pearson Correlation & 1 & $.683^{* *}$ \\
\cline { 2 - 4 } & Sig. (2-tailed) & 42 & .000 \\
\cline { 2 - 4 } & $\mathrm{N}$ & $.683^{* *}$ & 42 \\
\hline \multirow{3}{*}{ English reading comprehension } & Pearson Correlation & .000 & 1 \\
\cline { 2 - 4 } & Sig. (2-tailed) & 42 & 42 \\
\cline { 2 - 4 } & $\mathrm{N}$ & & 42 \\
\hline
\end{tabular}

** Correlation is significant at the 0.01 level (2-tailed).

As shown in Table 2, the Pearson's correlation between FD-FI cognitive style and English reading performance suggested that the effect size of the correlation was large, and the CI was fairly wide (95\% CI; R2=0.407, N=42, $\mathrm{r}=0.683$ ). There was a significant relationship between FD-FI cognitive style and English reading performance (according to Pearson's correlation coefficient, $\mathrm{r}=0.683$, $\mathrm{P}<0.01$ ). This indicated that the participants with FI cognitive style performed better than those with FD cognitive style in English reading performance.

As mentioned before, reading comprehension reflects and individuals' ability in absorbing, processing and organizing information, while FDFI cognitive style concerns the individuals' ability to organize information in an analytical way and for cognitive reconstruction. ${ }^{[25]}$ Therefore, students who have excellent information processing and reconstruction were more likely to have better performance in the reading comprehension test.

To further determine whether there were significant differences between the FD group and FI group in English reading performance, independent sample t-test was done. Scores 12 and below were categorized in the FD group and those above were categorized in FI group (see Table 3).

Table 3. Group Statistics of FD-FI cognitive style and English reading performance

\begin{tabular}{lccccc}
\hline & FD-FI & N & Mean & Std. Deviation & Std. Error Mean \\
\hline English reading comprehension & FD & 8 & 21.25 & 4.773 & 1.688 \\
& FI & 34 & 27.53 & 4.698 & .806 \\
\hline
\end{tabular}

Table 3 shows the group statistics of FD-FI cognitive style and English reading performance. Among 42 students, 8 of them had FD cognitive styles and 34 of them had FI cognitive styles, which showed that a large number of them were more likely to have FI cognitive style. For FD students, the mean score of the reading test was 21.25 and the standard deviation was 4.773. For FI students, their mean score was 27.53, and the standard deviation was 4.698.

According to the independent sample t-test, the English reading performance of students with FD cognitive style was significantly different from those with FI cognitive style $(\mathrm{t}(40)=3.392$, $\mathrm{P}=0.002<0.05$ ), suggesting that the FI group had significantly higher scores than the FD group in the reading comprehension test. This result is consistent with previous studies on the relationship between FD-FI cognitive style and English reading comprehension. FI learners are adept at separating important information from those of less significance as they have analytical minds, while FD learners are easily affected by their surroundings. Therefore, FI learners will tend to focus on specific questions in the reading test instead of being influenced by irrelevant 
information, thus having higher accuracy. On the other hand, FD group is inclined to read the text from a holistic approach, thus failing to reach to the point quickly and accurately.

\subsection{Relationship between working memory and English reading performance}

42 postgraduates have participated in the research, and the data collected were valid (see Table 4).

Table 4. Descriptive statistics of working memory and English reading performance

\begin{tabular}{lccccc}
\hline & $\mathrm{N}$ & Minimum & Maximum & Mean & Std. Deviation \\
\hline WM & 42 & 1 & 5 & 2.90 & 1.078 \\
English reading & 42 & 14 & 38 & 26.33 & 5.281 \\
Valid N (listwise) & 42 & & & & \\
\hline
\end{tabular}

According to Table 4, there was a significant difference of 24 points between the maximum (38 points) and the minimum (14 points) points in the reading test, whereby the mean score was 26.33 . In the working memory test, the total score was 7 , the mean score was 2.90, and the standard deviation was 1.078. The large difference in points indicated a significant difference between student's WM. Table 5 shows the correlation between working memory and English reading correlation.

Table 5. Correlation between WM and English reading performance

\begin{tabular}{|c|c|c|c|}
\hline & & Working memory & $\begin{array}{l}\text { English reading } \\
\text { comprehension }\end{array}$ \\
\hline \multirow{3}{*}{$\begin{array}{l}\text { Working } \\
\text { memory }\end{array}$} & Pearson Correlation & 1 & $.563 * *$ \\
\hline & Sig. (2-tailed) & & .000 \\
\hline & $\mathrm{N}$ & 42 & 42 \\
\hline \multirow[t]{3}{*}{ English reading comprehension } & Pearson Correlation & $.563 * *$ & 1 \\
\hline & Sig. (2-tailed) & .000 & \\
\hline & $\mathrm{N}$ & 42 & 42 \\
\hline
\end{tabular}

** Correlation is significant at the 0.01 level (2-tailed).

The Pearson's correlation between WM and English reading performance in Table 5 suggested that the effect size of the correlation was large, and the CI was fairly wide $(95 \% \mathrm{CI}$; R2 $=0.317, \mathrm{~N}=42$, $\mathrm{r}=0.563$ ). There was a significant relationship between WM and English reading performance according to the Pearson's correlation coefficient, $\mathrm{r}=0.563, \mathrm{P}<0.01$. This indicated that students with high WMC performed better than those with low WMC in English reading performance. This result is in line with the study of Andy that suggested WM and English reading performance were closely related, and WM is responsible for the complex mental processing and executive functioning, which are important for high-level cognitive activities, like reading comprehension. ${ }^{[26]}$ As the model of WM suggests, working memory concerns the storage and processing of information, whereby, the higher the WMC the reader has, the more information they can store to deal with the reading comprehension questions. The information stored in WM is directly used to answer the questions within a limited time whereby the old information quickly integrates with the new information. To some extent, the measure of WM itself can be regarded as a reading test. It is an essential part in reading comprehension and is closely related with English reading performance.

To conclude whether there were significant differences between high and low WMC groups in 
English reading performance, the independent sample t-test was conducted. Those with scores 3 and below were categorized to the low WMC group and those above were placed in the high WMC group (see Table 6).

Table 6. Group statistics of WM and English reading performance

\begin{tabular}{lcccc}
\hline & WM & N & Mean & Std. Deviation \\
\hline English reading comprehension & High & 28 & 28.71 & 3.971 \\
& Low & 14 & 21.57 & 4.309 \\
\hline
\end{tabular}

From Table 6, among 42 students, 28 of them were placed in the high WMC group whereas 14 of them were placed in the low WMC group. The mean score of the reading test among the high WM group was 28.71 while that of low WM group was 21.57, which indicated that the reading performance of students with different WMC had variation.

According to the independent sample t-test, the English reading performance of students with high WMC was significantly different from those with low WMC $(\mathrm{t}(40)=5.343, \mathrm{P}<0.05)$. This showed that the high WMC group had obtained significantly higher scores than the low WMC group in the reading comprehension test. This result is in line with that of Daneman and Carpenter. Factors like distribution of cognitive resources, attention and knowledge base are likely to influence the learners' working memory, thus leading to different performance in reading comprehension test.

\subsection{Relationship among FD-FI cognitive style, working memory and English reading performance}

To examine the relationship among FD-FI cognitive style, working memory and English Reading Performance, a $2 \times 2$ between-subjects ANOVA was conducted with English reading performance as the dependent variable, whereas WM and FD-FI cognitive style were the independent variables (see Table 7).

Table 7. Descriptive statistics of FD-FI cognitive style, WM, and English reading performance

Dependent variable: English reading comprehension

\begin{tabular}{|c|c|c|c|c|}
\hline FDFI & WM & Mean & Std. Deviation & $\mathrm{N}$ \\
\hline \multirow[t]{3}{*}{ FD } & Low & 19.20 & 4.147 & 5 \\
\hline & High & 24.67 & 4.163 & 3 \\
\hline & Total & 21.25 & 4.773 & 8 \\
\hline \multirow[t]{3}{*}{ FI } & Low & 22.89 & 4.014 & 9 \\
\hline & High & 29.20 & 3.742 & 25 \\
\hline & Total & 27.53 & 4.698 & 34 \\
\hline \multirow[t]{3}{*}{ Total } & Low & 21.57 & 4.309 & 14 \\
\hline & High & 28.71 & 3.971 & 28 \\
\hline & Total & 26.33 & 5.281 & 42 \\
\hline
\end{tabular}

According to Table 7, there are 34 FI students, whereby the mean score of their reading test was 27.53. Among them, 25 have high WMC and the mean score was 29.20. On the other hand, the mean score for the low WMC group was only 22.89. Eight students had FD cognitive style, whereby the mean score was 21.25 , and 5 of them were in the low WMC group. Data showed that students with 
FI cognitive style performed better than those with FD cognitive style in the reading comprehension test, and students with high WMC performed better than those with low WMC. The mean score of FD students with low WMC was the lowest.

Table 8 shows the tests of between-subjects effects of FD-FI cognitive style, working memory and English reading performance.

Table 8. Between-subjects effects of FD-FI cognitive style, WM, and English reading performance

Dependent variable: English reading comprehension

\begin{tabular}{|c|c|c|c|c|c|}
\hline Source & Type III sum of squares & $\mathrm{df}$ & Mean square & $\mathrm{F}$ & Sig. \\
\hline $\begin{array}{l}\text { Corrected } \\
\text { model }\end{array}$ & $574.978 \mathrm{a}$ & 3 & 191.659 & 12.814 & .000 \\
\hline Intercept & 13452.470 & 1 & 13452.470 & 899.426 & .000 \\
\hline FDFI & 98.773 & 1 & 98.773 & 6.604 & .014 \\
\hline WM & 202.670 & 1 & 202.670 & 13.550 & .001 \\
\hline FDFI x WM & 1.042 & 1 & 1.042 & .070 & .793 \\
\hline Error & 568.356 & 38 & 14.957 & & \\
\hline Total & 30268.000 & 42 & & & \\
\hline Corrected total & 1143.333 & 41 & & & \\
\hline
\end{tabular}

a. $\mathrm{R}$ Squared $=.503$ (Adjusted R Squared $=.464$ )

b. Computed using alpha $=.05$

According to Table 8, there was a main effect of WM $(\mathrm{F}(1,38)=13.550, \mathrm{P}<0.05)$, which meant that students with high WM had better performance than those with low WM in the English reading test. There was also a main effect of FD-FI cognitive style $(\mathrm{F}(1,38)=6.604, \mathrm{P}<0.05)$, which meant that $\mathrm{FI}$ students obtained higher grades than FD students in the English reading comprehension test. However, there was no significant correlation between working memory and FI-FD cognitive style $(F(1,38)=0.070, P>0.05)$, while the main effect of both WM and FD-FI cognitive style was significant.

\section{Conclusion}

This study examined the correlation among working memory, FD-FI cognitive style and English reading comprehension. The main findings are as below:

First, there was a significant relationship between FD-FI cognitive style and English reading comprehension performance $(\mathrm{r}=0.638, \mathrm{P}<0.01)$. There was also a significant difference between students of FD with FI cognitive style in the reading test $(\mathrm{t}(40)=3.392, \mathrm{P}=0.002<0.05)$. This showed that the FI group had significantly higher scores than the FD group in the reading comprehension test. While FI students have the tendency to process and reconstruct information presented in an analytical way, FD students, on the other hand, rely more on the surroundings and are easily influenced by irrelevant information, thus leading them to misunderstandings.

Second, working memory had a significant relationship with English reading performance $(\mathrm{r}=0.563, \quad \mathrm{P}<0.01)$. The English reading performance of students with high WMC was significantly different from those with low WMC $(\mathrm{t}(40)=5.343, \mathrm{P}<0.05)$. This showed that the high WMC group had significantly higher scores than the low WMC group in the reading comprehension test. Both WM and reading comprehension test are related to information storage and processing. When less cognitive resources are distributed to process information, it is balanced by more cognitive resources being distributed for information storage. Therefore, an individual is 
able to maintain more information in their minds when information processing is not required.

Third, the main effect of working memory $(\mathrm{F}(1,38)=13.550, \mathrm{P}<0.05)$, and $\mathrm{FD}-\mathrm{FI}$ cognitive style $(\mathrm{F}(1,38)=6.604, \mathrm{P}<0.05)$, on English reading performance was significant, respectively. However, the relationship of FD-FI cognitive style and working memory was not significant in English reading performance $(\mathrm{F}(1,38)=0.070, \mathrm{P}>0.05)$.

The implication of this study contributes to both, teachers and students. For English teachers, it is necessary for them to teach effective reading strategies to improve their students' reading performance. For example, highlighting key words during reading comprehension is beneficial as it can help students to focus on key information rather than being distracted by irrelevant ones. Under the guidance of teachers, students may use these reading strategies. On the other hand, for students, they will be able to have an in-depth understanding of their own cognitive style and working memory. This may motivate them to improve their WM. For example, developing knowledge and skills of memorizing vocabulary would enhance their WM efficiently. In addition to that, teachers may also request their students to recall contents after each lesson to strengthen their memory.

In this study, there were some limitations. For example, its small sample size and the primary focus on only one aspect of students' language ability which is the reading comprehension. Therefore, further studies should be encouraged to investigate other significant language skills like the English listening, writing, speaking, translation, and other skills.

\section{Disclosure statement}

No conflicts of interest.

\section{References}

[1] Messick, S(2009). The Nature of Cognitive Styles: Problems and Promise in Educational Practice. Educational Psychologist, 19(2): 59-74. [2] Jourdain, $\quad \mathrm{S}(2010)$. Second Language
Acquisition: An Introductory Course. The Modern Language Journal, 94(2): 348-349.

[3]Zhang, M., et al(2020). Effect of Cognitive Style on Language Control during Joint Language Switching: An ERP Study. Journal of Psycholinguistic Research, 49(3): 1-18.

[4] Baddeley, A(2003). Working Memory and Language: An Overview. Journal of Communication Disorders, 36(3): 189-208.

[5] Witkin, H(1971). A. et al. Field-dependent and Field-independent Cognitive Style and Their Educational Implication. Review of Educational Research, (47): 1-64.

[6]Ehrman, M., Leaver, B. \& Seyyedrezaie, S(2003). A Brief Overview of Individual Differences in Second Language Learning. System, (31): 313-333.

[7] Cassidy, S(2004). Learning styles: An Overview of Theories, Models and Measures. Educational Psychology, (24): 419-444.

[8] Baddeley, A., et al(2010). Is the Hippocampus Necessary for Visual and Verbal Binding in Working Memory?. Neuropsychologia, 48(4): 1089-1095.

[9] Baddeley, A(2000). The Episodic Buffer: A New Component of Working Memory?. Trends in Cognitive Science, 4: 417-423.

[10]Baddeley, A, Hitch, G(1974). Working memory. Psychology of Learning and Motivation. 8:47-89.

[11]Daneman, M., Carpenter, P(1980). Individual differences in working memory and reading. Journal of Verbal Learning \& Verbal Behavior, 19(4): 450-466.

[12]Miller, G(1995). The Magical Number Seven, plus or minus Two Some Limits on Our Capacity for Processing Information. Harvard University Press, 15.

[13]Goodman, K(1999). A Psycho-linguistic Guessing Game. Journal of the Reading Specialist, 126-135.

[14]Sabet, M., Mohammadi, S(2013). The Relationship between Field Independence/Field Dependence Styles and Reading Comprehension Abilities of EFL Readers. Theory and Practice in Language Studies, 3(11): 2041-2150. 
[15]Nozari, A., Siamian, H(2015). The Relationship between Field DependentIndependent Cognitive Style and Understanding of English Text Reading and Academic Success. Materia Socio Medica, 27(1): 39-41.

[16]Dai, Y(2002). FI-FD Cognitive Style and Second Language Acquisition. Foreign Language Teaching and Research, 34(3): 203-240.

[17]Xu, W(1999). FI-FD Cognitive Style and College English Teaching. Foreign Language and Their Teaching, 4: 52-52. •

[18]Andy, V., Ramzi, M(2014). Verbal and Visuospatial Working Memory as Predictors of Children Reading Ability. Archives of Clinical Neuropsychology, 29: 467-477.

[19]Wei, J., Ni, C(2018). A Study on the Relationship between Working Memory and L2 Proficiency Level. Foreign Language and Their Teaching, 4: 51-56.

[20]Kerry, A., Emily, E(2018). Does Accuracy and Confidence in Working Memory Performance Relate to Academic Achievement in NAPLAN, the Australian National Curriculum Assessment. Australian Journal of Psychology, 3: 1-8.

[21]Lisbeth, M., Glenn, O(2019). Outliers: Upper
Secondary School Students Who Read Better in the L2 than in L1. International Journal of Educational Research, (89): 80-91.

[22]Grimley, M., Banner, G(2008). Working Memory, Cognitive Style, and Behavioural Predictors of GCSE Exam Success. Educational Psychology, 28(3): 341-351.

[23]Alloway, T., et al(2010). Working Memory and Cognitive Styles in Adolescents' Attainment. Journal of Education Psychology, (80): 567-581. [24] Keene, F(2017). The Effect of Learners' Field Independence, Cognitive Strategy Instruction, and Inherent Word-list Organization on Free-recall Memory and Strategy Use. The Journal of Experimental Education, 62(1): 14-25.

[25]Umah, U(2020). Comparison of Students' Covariational Reasoning based on Differences in Field-dependent and Field-independent Cognitive Style. Journal Matematika dan Pendidikan Matematika, 4(1): 41-54.

[26]Wang, X(2017). The Enlightenment of Cognitive Style Differences between Field Dependent and Field Independent Mode on College English Teaching. Journal on Studies in English Language and Literature, 5(6): 31-37. 